\title{
EL FORTALECIMIENTO DE LA INDEPENDENCIA JUDICIAL EN LOS PROCESOS DE JUSTICIA TRANSICIONAL COMO GARANTÍA DE NO REPETICIÓN*
}

\author{
Elisenda CALVET Martínez \\ Xavier PONS RÀFOLS **
}

SUMARIO: 1 . INTRODUCCIÓN.-2. LAS GARANTÍAS DE NO REPETICIÓN COMO MECANISMO DE JUSTICIA TRANSICIONAL.-2.1. Las garantías de no repetición como forma de reparación en el Derecho internacional.-2.2. Las garantías de no repetición como medidas distintas de la reparación en el Derecho internacional.-3. LA INDEPENDENCIA JUDICIAL COMO COMPONENTE ESENCIAL DEL ESTADO DE DERECHO.-3.1. Formulación y evolución de la noción de Estado de Derecho en el Derecho internacional.-3.2. Contenido y alcance de la independencia judicial en el Derecho internacional.- 4. LA JUSTICIA TRANSICIONAL Y EL PODER JUDICIAL.-4.1. La complicidad del poder judicial en las graves violaciones de los derechos humanos.-4.2. Las reformas del poder judicial como garantía de no repetición.-5. CONSIDERACIONES FINALES.

\section{INTRODUCCIÓN}

1. En muchas situaciones recientes de postconflicto ha ido adquiriendo carta de naturaleza la justicia transicional como un mecanismo que resulta adecuado para restañar las profundas heridas que el conflicto armado, tanto internacional como interno, ha dejado y favorecer procesos de institucionalidad democrática en condiciones de seguridad, estabilidad y perdurabilidad. En este sentido, la justicia transicional comprende un conjunto de medidas, de carácter judicial y no judicial, que tienen por objeto hacer frente a las graves violaciones de los derechos humanos cometidas en el pasado, luchando

* El presente estudio se enmarca en el proyecto de investigación Fortaleciendo la independencia judicial en procesos de justicia transicional como una garantía de no repetición de graves violaciones de derechos humanos. Estudio de tres casos: España, Argentina y Guatemala (2015RICIP00002), financiado por el Institut Català Internacional per la Pau, del cual es investigadora principal Elisenda Calvet Martínez, investigadora postdoctoral en Derecho Internacional Público y coordinadora de la Clínica Jurídica de Lucha contra la Impunidad de la Universidad de Barcelona (elisendacalvet@ub.edu). Todas las páginas web de referencia han sido consultadas por última vez el 16 de diciembre de 2017.

** Catedrático de Derecho Internacional Público de la Universidad de Barcelona (xpons@ub.edu). 
contra la impunidad y favoreciendo, al mismo tiempo, la democratización. La adopción, por parte de las Naciones Unidas, del Conjunto de principios de lucha contra la Impunidad ${ }^{1}$, así como también de los Principios y las Directrices sobre Reparación de las víctimas de graves violaciones de los derechos humanos ${ }^{2}$, ha contribuido, sin duda, al establecimiento de un marco jurídico-internacional de la justicia transicional sobre la base del derecho a la verdad, el derecho a la justicia, el derecho a la reparación y las garantías de no repetición. De entre estos distintos componentes de la justicia transicional, y a los efectos que interesan en este estudio, las garantías de no repetición comprenden todas las medidas que debe adoptar un Estado para reducir la probabilidad de que se repitan las graves violaciones de los derechos humanos y del Derecho internacional humanitario ocurridas en el pasado.

2. Estas necesarias reformas institucionales que deben realizar los Estados en procesos de justicia transicional no han sido objeto de un amplio estudio doctrinal y, a menudo, en la misma práctica internacional, han quedado en un segundo plano ${ }^{3}$. Sin embargo, muchos de los informes de las comisiones de la verdad contienen recomendaciones y programas para prevenir la recurrencia de conflictos en un futuro ${ }^{4}$. Por ejemplo, la Comisión de la Verdad y Reconciliación de Sierra Leona contiene recomendaciones sobre el establecimiento del Estado de Derecho, y considera que el punto de partida es la creación de un poder judicial independiente, imparcial y autónomo ${ }^{5}$.

3. Pese a que en el marco de las reformas institucionales las más destacadas son, seguramente, las relativas a las fuerzas armadas y a los cuerpos de seguridad y de inteligencia, el poder judicial también juega un papel relevante en los procesos de justicia transicional, puesto que su independencia, imparcialidad y eficacia son fundamentales para garantizar los derechos de las víctimas y para poder investigar, enjuiciar y, en su caso, castigar a las personas responsables de las atrocidades cometidas en el pasado. A todo lo cual cabe añadir que, a menudo, el conjunto del sistema judicial ha sido también cómplice de estas violaciones de los derechos humanos. En este sentido, varias comisiones de la verdad han revelado el papel del poder judicial en con-

\footnotetext{
1 Comisión de Derechos Humanos, Conjunto de principios actualizado para la protección y la promoción de los derechos humanos mediante la lucha contra la impunidad, ONU Doc. E/CN.4/2005/102/ Add.1, de 8 de febrero de 2005.

2 Asamblea General de las Naciones Unidas, Principios y directrices básicos sobre el derecho de las víctimas de violaciones manifiestas de las normas internacionales de derechos humanos y de violaciones graves del derecho internacional humanitario a obtener recursos y obtener reparaciones, ONU Doc. A/ RES/60/146, de 16 de diciembre de 2005.

3 SKAAR, E., «¿Puede la independencia judicial explicar la justicia postransicional? Does Judicial Independence explain Post-transitional Justice?», América Latina Hoy, vol. 61, 2012, pp. 15-49.

${ }^{4}$ Véase, entre otros, SHARP, D. N., "Interrogating the peripheries: the preoccupations of fourth generation transitional justice», Harvard Human Rights Journal, vol. 26, 2013, pp. 149-178.

5 Report of Sierra Leone Truth and Reconciliation Commission, vol. 2, cap. 3. La Comisión hizo un llamamiento a los operadores de justicia para que actuaran con integridad en todas las circunstancias y administraran justicia sin miedo y sin favores, y estableció recomendaciones imperativas y otras más a largo plazo para el establecimiento del Estado de Derecho.
} 
textos de conflicto armado o regímenes autoritarios, en los que en muchas ocasiones desvió el foco hacia otro lado, no tramitó los recursos de habeas corpus interpuestos por los familiares de las víctimas o no practicó las diligencias adecuadas para investigar realmente los casos que implicaban a la policía, a las fuerzas armadas o al poder ejecutivo, ya fuera por afinidad al régimen o por miedo a represalias.

4. La justicia transicional debería tener, así, como principal objetivo la prevención y las garantías de no repetición —el nunca más-, considerando que la democratización y el establecimiento de un Estado de Derecho previenen - de la forma más efectiva, estable y segura- el retorno a las atrocidades, al ofrecer un control del abuso de poder y medios legales y pacíficos para abordar los conflictos y agravios que dieron lugar a las violaciones de los derechos humanos ${ }^{6}$. En este orden de ideas, este trabajo pretende analizar, desde la perspectiva del Derecho internacional, en qué medida las reformas institucionales del poder judicial encaminadas a fortalecer la independencia judicial en procesos de justicia transicional constituyen una garantía de no repetición, en el sentido de prevenir que vuelvan a producirse las graves violaciones de los derechos humanos ocurridas en el pasado.

5. A tal efecto, se analiza, en primer lugar, el contenido y alcance de las garantías de no repetición en tanto que mecanismo de justicia transicional, tal como ha sido reflejado en el Derecho internacional (2). En segundo lugar, se aborda la noción de la independencia judicial en el Derecho internacional, situándola como un elemento esencial del Estado de Derecho (3). Bajo estas dos premisas, se analizan, en tercer lugar, tanto las situaciones de complicidad del poder judicial con las violaciones de los derechos humanos del pasado como las necesarias reformas que han de hacerse en el poder judicial para conseguir que recupere su legitimidad y su independencia e imparcialidad, indispensables para garantizar el Estado de Derecho en las nuevas democracias o en las situaciones de postconflicto (4).

\section{LAS GARANTÍAS DE NO REPETICIÓN COMO MECANISMO DE JUSTICIA TRANSICIONAL}

6. En el marco de la justicia transicional, las garantías de no repetición suelen interpretarse como una forma de reparación ${ }^{7}$ o como una forma de satisfacción en un sentido más amplio ${ }^{8}$, si bien también pueden considerarse

\footnotetext{
6 Andersen, E., "Transitional Justice and the Rule of Law: Lesson from the Field», Case Western Reserve Journal of International Law, vol. 47, 2015, pp. 305-318, esp. p. 309.

7 Laplante, L. J., "Bringing Effective Remedies Home: The Inter-American Human Rights System. Reparations, and the Duty of Prevention», Netherlands Quarterly of Human Rights, vol. 22, 2004, pp. 347-388. La autora considera que la reparación tiene dos funciones: reparar el daño y prevenir futuras violaciones.

8 FERnÁndez SOLÁ, N., «El derecho a la reparación de las víctimas de desaparición forzada: hacia la justicia a través del derecho internacional», Revista Española de Derecho Internacional, vol. LX, 2008, núm. 2, pp. 397-425, esp. p. 418. Véase también, Comité DE Derechos Humanos, Observación general
} 
que son medidas específicas diferentes de la reparación ${ }^{9}$. En este sentido, las garantías de no repetición hacen referencia a todas aquellas medidas que debe adoptar el Estado "para que las víctimas no puedan volver a ser objeto de violaciones de sus derechos» ${ }^{10} \mathrm{y}$, por tanto, constituyen, sobre todo, medidas de prevención para reducir la probabilidad de que se repitan en el futuro graves violaciones de los derechos humanos, fruto normalmente de los abusos sistemáticos de los poderes del Estado ${ }^{11}$. Además, las garantías de no repetición deben ser específicas del contexto y tratar con las causas y los efectos de las violaciones de los derechos humanos para prevenir violaciones específicas que ya tuvieron lugar y que pudieran volver a ocurrir ${ }^{12}$.

7. También es importante resaltar que las garantías de no repetición tienen por objeto la sociedad en su conjunto, mientras que la verdad, la justicia y la reparación son derechos que corresponden a las víctimas y a sus familiares, y solo en última instancia a la sociedad ${ }^{13}$. Por otra parte, las transformaciones que se requieren para promover las garantías de no repetición de las graves violaciones de los derechos humanos ocurridas en el pasado no son solo reformas institucionales, sino que también se requieren actuaciones en el ámbito cultural e individual para conseguir transformaciones duraderas ${ }^{14}$. Dentro de las distintas medidas que se pueden adoptar, el fortalecimiento de la independencia judicial constituye una de las garantías de no repetición contempladas tanto por los Principios y Directrices Básicos sobre Reparación ${ }^{15}$ como por el Conjunto de Principios contra la Impunidad de las Naciones Unidas ${ }^{16}$.

8. A estos efectos, se aborda ahora la noción y alcance de las garantías de no repetición desde la perspectiva, por una parte, de la reparación, a partir de los Principios y Directrices Básicos sobre Reparación y del Derecho internacional de los derechos humanos (2.1); y, por otra, entendiendo las garantías de no repetición como medidas distintas a la reparación, sobre la base del Conjunto de Principios contra la Impunidad y las normas del Derecho internacional en materia de responsabilidad internacional del Estado (2.2).

núm. 31 [80] Naturaleza de la obligación jurídica general impuesta a los Estados Partes en el Pacto, ONU Doc. CCPR/C/21/Rev.1/Add.13, de 26 de mayo de 2004, párr. 16.

9 DE GReIfF, P., «Justice and Reparations», en DE GReIFF, P. (ed.), The handbook of reparations, Oxford University Press, 2008, pp. 451-477, esp. p. 453. De Greiff prefiere utilizar el término «reparaciones» en un sentido estricto para referirse a las medidas que otorgan beneficios directos a las víctimas, para diferenciarlo de las medidas que pueden tener un efecto reparatorio y que también pueden ser importantes, como el castigo de los perpetradores o las reformas institucionales, pero que no tienen un beneficio directo para las propias víctimas.

${ }_{10}$ Véase Conjunto de principios actualizado..., op. cit., nota 1, Principio 35.

${ }^{11}$ Consejo de Derechos Humanos, Informe del Relator Especial sobre la promoción de la verdad, la justicia, la reparación y las garantías de no repetición, ONU Doc. A/HRC/30/42, de 7 de septiembre de 2015, párr. 25.

12 MaYeR-RIECKH, A., «Guarantees of Non-Recurrence. An approximation», Human Rights Quarterly, vol. 39, 2017, núm. 2, pp. 416-448, esp. p. 447.

${ }_{13}$ MéNDEZ, J., «Accountability for past abuses», Human Rights Quarterly, vol. 19, 1997, pp. 255282, esp. p. 261.

${ }_{14}$ Véase ONU Doc. A/HRC/30/42, op. cit., nota 11, párrs. 32-35.

15 Véase Principios y directrices básicos..., op. cit., nota 2, Principio 23.c).

${ }_{16}$ Véase Conjunto de principios actualizado..., op. cit., nota 1, Principio 36.b). 


\subsection{Las garantías de no repetición como forma de reparación en el Derecho internacional}

9. Las garantías de no repetición como una forma de reparación de graves violaciones de los derechos humanos fueron incorporadas por primera vez en un informe de 1993 elaborado por Theo Van Boven durante sus travaux préparatoires sobre los Principios y Directrices Básicos sobre Reparación adoptados en el 2005. Para ello, el experto de las Naciones Unidas se basó en los trabajos realizados por la Comisión de Derecho Internacional (CDI) sobre la responsabilidad internacional del Estado, además de tener en cuenta la jurisprudencia y decisiones del Comité de Derechos Humanos, el Tribunal Europeo de Derechos Humanos y la Corte Interamericana de Derechos Humanos ${ }^{17}$.

10. Los Principios y Directrices Básicos sobre Reparación pueden considerarse, así, una guía y orientación para los Estados en materia de reparación para las víctimas de violaciones de los derechos humanos y del Derecho internacional humanitario. En ellos se consideran las garantías de no repetición como una forma de reparación junto con la restitución, la indemnización, la rehabilitación y la satisfacción ${ }^{18}$. En este sentido, el Principio 23 contiene una lista no exhaustiva de garantías de no repetición que se pueden adoptar, en su totalidad o en parte, con el objeto de contribuir a la prevención de futuras violaciones y que comprende diferentes medidas estructurales, como las reformas institucionales orientadas a asegurar el control civil de las fuerzas militares y de seguridad, el fortalecimiento de la independencia judicial, la protección de los defensores de los derechos humanos, la educación en materia de derechos humanos de todos los sectores de la sociedad y la derogación o reforma de las leyes que contribuyan a la vulneración de graves violaciones de los derechos humanos.

11. En el ámbito del Derecho internacional de los derechos humanos, la Convención Internacional para la protección de todas las personas contra las desapariciones forzadas de 2006, seguramente influida por los Principios y Directrices Básicos sobre Reparación, recoge de forma expresa diversas formas de reparación, entre las que incluye, asimismo, las garantías de no repetición ${ }^{19}$. En este sentido, las instancias internacionales de protección de los derechos humanos han resaltado la vinculación entre el derecho a un recurso efectivo de las víctimas y las medidas de prevención que garantizan el respeto de los derechos humanos porque, a menudo, las violaciones de los

17 Comisión de Derechos Humanos, Estudio relativo al derecho de restitución, indemnización y rehabilitación a las víctimas de violaciones flagrantes de los derechos humanos y las libertades fundamentales, Informe definitivo presentado por el Sr. Theo van Boven, Relator Especial, ONU Doc. E/CN.4/ Sub.2/1993/8, de 2 de julio de 1993.

18 Véase Principios y directrices básicos..., op. cit., nota 2, Principio 18.

19 Art. 24.5.d) de la Convención adoptada por la Asamblea General de las Naciones Unidas mediante la Resolución 61/177, de 20 de diciembre de 2006, BOE núm. 42, de 18 de febrero de 2011. 
derechos humanos implican también la presencia de recursos ineficaces o inoperativos ${ }^{20}$. En un contexto de impunidad es probable que el derecho de reparación de las víctimas sea una mera ilusión, puesto que «resulta difícil de imaginar un sistema judicial que vele por los derechos de las víctimas y se mantenga al mismo tiempo indiferente e inactivo ante los flagrantes delitos de quienes los han violado» ${ }^{21}$.

12. Para el Comité de Derechos Humanos, la obligación básica de respetar y garantizar los derechos humanos no tendría sentido si los Estados no adoptaran «medidas que impidan la repetición de una violación del Pacto» de manera que, además de los recursos que se pongan al alcance de la víctima, los Estados deben tomar medidas para impedir la repetición de violaciones del mismo tipo como, por ejemplo, «exigir la introducción de modificaciones en la legislación o la práctica de los Estados Parte» ${ }^{22}$. Asimismo, el Comité contra la Tortura considera también las garantías de no repetición como una forma de reparación y, para que no se repitan las torturas o los malos tratos, entiende que los Estados partes deben adoptar medidas para que el incumplimiento de la Convención no quede impune como, por ejemplo, reforzando la independencia judicial. En este mismo sentido, el Comité contra la Tortura destaca que las garantías de no repetición «encierran un gran potencial de transformación de las relaciones sociales que tal vez sean las causas profundas de la violencia y pueden incluir, entre otras, la enmienda de las leyes pertinentes, la lucha contra la impunidad y la adopción de medidas preventivas y disuasivas eficaces» ${ }^{23}$. De modo que, en el ámbito de los derechos humanos, el objetivo de las garantías de no repetición acaba siendo el de cambiar las leyes y prácticas de los Estados, mejorando así el nivel de protección de los derechos humanos ${ }^{24}$.

\subsection{Las garantías de no repetición como medidas distintas de la reparación en el Derecho internacional}

13. El Conjunto de Principios contra la Impunidad recoge las obligaciones generales de los Estados de investigar las graves violaciones de los derechos humanos, procesar a las personas responsables de estos graves delitos, garantizar a las víctimas recursos eficaces y una reparación integral y tomar

20 Laplante, L., op. cit., nota 7, p. 361. Véase también, ONU Doc. E/CN.4/Sub.2/1993/8, op. cit., nota 17 , párr. 55 .

21 Comisión de Derechos Humanos, Estudio relativo al derecho de restitución, indemnización y rehabilitación a las víctimas de violaciones flagrantes de los derechos humanos y las libertades fundamentales, segundo informe sobre la marcha de los trabajos presentados por el Sr. Theo van Boven, Relator Especial, ONU Doc. E/CN.4/Sub.2/1992/8, de 29 de julio de 1992, párr. 55.

22 Comité de Derechos Humanos, Observación general núm. 31..., op. cit., nota 8, párr. 17.

23 Comité Contra la Tortura, Observación General núm. 3, aplicación del artículo 14 por los Estados Partes, ONU Doc. CAT/C/GC/3, de 13 de diciembre de 2012, párr. 18.

${ }^{24}$ Hillebrecht, C., «The power of human rights tribunals: Compliance with the European Court of Human Rights and domestic policy change», European Journal of International Relations, vol. 24, 2014, núm. 4, pp. 1100-1123. 
todas las medidas necesarias para evitar la repetición de dichas violaciones. Además, establece que los cuatro elementos esenciales para luchar contra la impunidad son, como ya hemos indicado, el derecho a la verdad, el derecho a la justicia, el derecho a obtener reparación y las garantías de no repetición.

14. En todo caso, debe subrayarse que, a diferencia de los Principios y Directrices Básicos sobre Reparación, en el Conjunto de Principios contra la Impunidad las garantías de no repetición se encuentran ubicadas en una categoría separada a la del derecho a la reparación. De este modo, en el Conjunto de Principios contra la Impunidad la Sección IV (A) establece las formas de reparación que comprenden, según el Principio 34, la restitución, indemnización, rehabilitación y satisfacción; mientras que en la sección IV (B) se establecen las garantías de no repetición de las violaciones y para ello se dispone en el Principio 35 que los Estados deberán «emprender reformas institucionales y otras medidas necesarias para asegurar el respeto del imperio de la ley, promover y mantener una cultura de respeto de los derechos humanos, y restaurar o establecer la confianza pública en las instituciones gubernamentales». Esta distinción entre reparación y garantías de no repetición es también la que finalmente adoptó la CDI en materia de responsabilidad internacional del Estado y que el propio Theo Van Boven consideró finalmente que, desde la perspectiva legal, era la correcta ${ }^{25}$.

15. Sin embargo, en la primera propuesta del Conjunto de Principios contra la Impunidad elaborada por el experto de Naciones Unidas Louis Joinet, las garantías de no repetición de violaciones formaban parte del derecho a obtener una reparación al igual que en los Principios y Directrices Básicos sobre Reparación ${ }^{26}$. Para Louis Joinet, las garantías de no repetición comprendían tres medidas: la disolución de los grupos armados paraestatales, la derogación de leyes y medidas de excepción y finalmente la separación del cargo de altos funcionarios. Si bien en esta propuesta no se hacía una referencia explícita al poder judicial, en la primera propuesta del Conjunto de Principios contra la Impunidad - en el Principio 42- se establecía que «en cuanto a los magistrados, la decisión se adoptará teniendo en cuenta las garantías del Principio 32». Este Principio se refería al principio de inamovilidad de los jueces que estaba contemplado en la sección del derecho a la justicia. Fue más adelante, cuando la profesora Orentlicher, encargada de revisar el Conjunto de Principios contra la Impunidad, teniendo en cuenta «la importancia de prestar más atención a la reforma institucional como base de una justicia sostenible ${ }^{27}$, consideró que las garantías de no repetición

\footnotetext{
25 VAn Boven, Th., "Reparative Justice- Focus on Victims SIM Lecture 2007», Netherlands Quarterly of Human Rights, vol. 25, 2007, pp. 723-736, esp. p. 735.

${ }_{26}$ COMisión de Derechos Humanos, Informe final revisado acerca de la cuestión de la impunidad de los autores de violaciones de los derechos humanos (derechos civiles y políticos) preparado por el Sr. L. Joinet de conformidad con la resolución 1996/119 de la Subcomisión, ONU Doc. E/CN.4/Sub.2/1997/20/ Rev.1, de 2 de octubre de 1997, Anexo II.

27 Comisión de Derechos Humanos, Informe de Diane Orentlicher, Experta independiente encargada de actualizar el Conjunto de principios para la lucha contra la impunidad, ONU Doc. E/CN.4/2005/102, de 18 de febrero de 2005, párr. 66.
} 
debían constar en una sección distinta al derecho a obtener una reparación e incluir el nuevo y actual Principio 36 relativo a la reforma de las instituciones estatales, de entre las cuales está la del poder judicial.

16. En este orden de ideas, debe indicarse que en el marco de los trabajos preparatorios sobre responsabilidad internacional del Estado, si bien en un principio las garantías de no repetición (como medida ex ante) estaban incluidas como medidas de satisfacción, junto con las de cesación, restitución y compensación del daño ${ }^{28}$, a partir de 1992 la CDI consideró que, dentro de las distintas formas de reparación, era mejor separar las medidas de satisfacción de las garantías de no repetición, al entender que las primeras se daban para reparar el daño causado por un hecho internacionalmente ilícito, mientras que las segundas no tenían relación con el daño causado y podían darse, en ciertos casos, incluso cuando se hubiera reparado todo el daño ${ }^{29}$. De modo que la CDI concibió las garantías de no repetición como unas medidas orientadas hacia el futuro y caracterizadas por una función más bien preventiva y no tanto reparatoria ${ }^{30}$. Para la CDI, las garantías de no repetición estaban relacionadas con la recuperación de la confianza en una relación continuada y resultan más necesarias cuando el Estado lesionado tiene motivos para creer que la mera restauración de la situación preexistente no lo protege satisfactoriamente ${ }^{31}$. Ha de recordarse, sin embargo, que las normas en materia de responsabilidad internacional del Estado son aplicables solo entre Estados y, por tanto, difieren completamente del contexto de justicia transicional en el que las garantías de no repetición están principalmente dirigidas a las relaciones entre el Estado y los individuos.

17. Si bien en las relaciones interestatales las garantías de no repetición no tienen por qué ser siempre consideradas apropiadas, en el ámbito de los derechos humanos sí que resultan muy importantes ${ }^{32}$. Lo son atendiendo a que, en el ámbito de la justicia transicional, las reformas institucionales - como la del poder judicial para garantizar su independencia-contribuyen a recuperar la confianza de la ciudadanía en las instituciones del Estado y al

28 Véase, entre otros, COMISIÓn DE DEREcho InTERnACIONAL, Sexto informe sobre el contenido, las formas y los grados de la responsabilidad internacional (segunda parte del proyecto de artículos); y Modo de "hacer efectiva» la responsabilidad internacional y solución de las controversias (tercera parte del proyecto de artículos) por el Sr. Willem Riphagen, Relator Especial, ONU Doc. A/CN.4/389, de 2 de abril de 1985, pp. 9-10; Tercer informe sobre la responsabilidad de los Estados del Sr. Gaetano Arangio-Ruiz, Relator Especial, ONU Doc. A/CN.4/440 y Add.1, de 19 de julio de 1991, párr. 93.

29 Comisión de Derecho InTernacional, Actas resumidas de la $2288 .^{a}$ sesión, extracto del Anuario de la Comisión de Derecho Internacional, 1992, vol. I, párr. 52. La Comisión consideró que las garantías de no repetición no eran, en sentido estricto, una forma de reparación, motivo por el cual decidió que la satisfacción y las garantías de no repetición tenían que ir en dos artículos distintos.

30 Zwanenburg, M., «The Van Boven/Bassiouni Principles: An Appraisal», Netherlands Quarterly of Human Rights, vol. 24, 2006, pp. 641-668, esp. p. 664.

31 Comisión de Derecho InTERnACIONAL, Proyecto de artículos sobre la responsabilidad del Estado por hechos internacionalmente ilícitos, con comentarios, Anuario de la Comisión de Derecho Internacional, vol. II, 2001 (segunda parte), p. 95.

32 Shelton, D., «The United Nations Principles and Guidelines on Reparations: Context and Contents", en FEYTER, K. (ed.), Out of the ashes: reparation for victims of gross and systematic human rights violations, Intersentia nv, 2005, pp. 11-33, esp. p. 23. 
respeto de los derechos humanos. En este sentido, el Conjunto de Principios contra la Impunidad establece que las reformas institucionales deben llevarse a cabo mediante un proceso de consulta pública en el que participen, entre otros, la sociedad civil y las víctimas. Además, el Principio 34 establece que las garantías de no repetición deben promover los siguientes objetivos: el imperio de la ley, la derogación de las leyes que contribuyan a las violaciones de los derechos humanos, el control civil de las fuerzas militares y de seguridad y la reintegración a la sociedad de los menores que hayan participado en los conflictos armados. Cabe destacar, asimismo, que dentro de las reformas institucionales el Conjunto de Principios contra la Impunidad incluye el fortalecimiento de la independencia del poder judicial, con especial referencia al recurso de habeas corpus como un derecho inderogable ${ }^{33}$.

18. En definitiva, a pesar de que las garantías de no repetición estén categorizadas de forma distinta en los Principios y Directrices Básicos sobre Reparación y en el Conjunto de Principios contra la Impunidad, la esencia y el objeto son, a nuestro juicio, los mismos. Así, las garantías de no repetición en un contexto de justicia transicional se caracterizan por mirar hacia el futuro, constituyendo medidas de prevención que resultan necesarias, ya que existe el riesgo de que se repitan las graves violaciones de los derechos humanos ocurridas en el pasado. En este sentido, el derecho a la reparación corresponde a las víctimas, tanto de forma individual como colectivamente, mientras que las garantías de no repetición, como medidas que miran hacia el futuro, implican profundas reformas institucionales que han de servir para garantizar el respeto del Estado de Derecho y (r)establecer la confianza en las instituciones públicas ${ }^{34}$.

19. En consecuencia, estas medidas de prevención se dirigen principalmente a las instituciones responsables de ciertas violaciones de los derechos humanos y tienen como objetivo abordar las razones por las cuales los miem-

33 El derecho de habeas corpus se encuentra reconocido en el art. 9.4 del Pacto Internacional de Derechos Civiles y Políticos y en el art. 7.6 de la Convención Americana sobre Derechos Humanos, mientras que en el ordenamiento jurídico español este derecho tiene rango constitucional (art. 17.4) y está desarrollado por la Ley Orgánica 6/1984, de 24 de mayo, reguladora del procedimiento de «Habeas Corpus». Sobre el carácter inderogable de este derecho véase, entre otros, Comisión DE DERECHOs Humanos, ONU Doc. E/CN.4/Sub.2/1997/20/Rev.1, op. cit., nota 26, párr. 43, y Principio 39 (del Conjunto de Principios contra la impunidad propuesto por Sr. L. Joinet) por el que se establece que: «El habeas corpus, fuera cual fuese su denominación, deberá ser considerado un derecho fundamental de la persona y, como tal, deberá formar parte de la categoría de derechos inderogable». En este sentido, véase CORTE INTERAMERiCANA DE Derechos Humanos, El habeas corpus bajo suspensión de garantías (arts. 27.2, 25.1 y 7.6 Convención Americana sobre Derechos Humanos), Opinión Consultiva OC-8/87, de 30 de enero de 1987, en donde la Corte considera que «aquellos ordenamientos constitucionales y legales de los Estados Partes que autoricen, explícita o implícitamente, la suspensión de los procedimientos de hábeas corpus o de amparo en situaciones de emergencia, deben considerarse incompatibles con las obligaciones internacionales que a esos Estados impone la Convención [Americana de Derechos Humanos]»; COMITÉ DE DERECHOS Humanos, Observación general núm. 29. Estados de emergencia (artículo 4), ONU Doc. CCPR/C/21/ Rev.1/Add.11, de 31 de agosto de 2001, párr. 16. Por otra parte, Larry May considera que el habeas corpus debería tener el carácter de ius cogens, MAY, L., "Habeas Corpus and the Normative Jurisprudence of International Law», Leiden Journal of International Law, vol. 23, 2010, núm. 2, pp. 291-310, esp. p. 305.

34 VAN Boven, Th., op. cit., nota 25, p. 735. 
bros de estas instituciones cometieron las violaciones; de tal modo que las garantías de no repetición apuntan en gran medida a reformar las estructuras y los sistemas que permitieron, facilitaron o promovieron estas violaciones ${ }^{35}$. Reformar el poder judicial - cómplice a menudo de las graves violaciones de los derechos humanos del pasado- para fortalecer su independencia constituye claramente una garantía de no repetición y así queda reflejado tanto en los Principios y Directrices Básicos sobre Reparación como en el Conjunto de Principios contra la Impunidad.

\section{LA INDEPENDENCIA JUDICIAL COMO COMPONENTE ESENCIAL DEL ESTADO DE DERECHO}

20. Bajo el hilo argumental que estamos planteando, corresponde ahora abordar la conexión entre el Estado de Derecho y la independencia judicial, entendiendo su consolidación y fortalecimiento como un instrumento clave para asegurar, de manera estable y perdurable, un futuro democrático que restañe las heridas del conflicto. A tal efecto, nos ocupamos, en primer lugar, de la formulación y evolución en el Derecho internacional de la noción del Estado de Derecho (3.1). En segundo lugar, analizaremos el contenido y alcance de la independencia judicial en el Derecho internacional (3.2).

\subsection{Formulación y evolución de la noción de Estado de Derecho en el Derecho internacional}

21. La noción de Estado de Derecho es un complejo concepto que, aunque pueda considerarse como de validez universal, tiene en los diversos ordenamientos internos alcance y contenido distintos, no habiéndose alcanzado hasta el momento una conceptualización precisa del mismo en instrumentos jurídicos internacionales adoptados por los Estados. En cualquier caso, se trata de una noción que, ciertamente, está presente también, aunque de una forma mucho más reciente, en el Derecho internacional contemporáneo ${ }^{36}$. El enfoque desde el Derecho internacional que nos interesa está directamente relacionado con los derechos humanos y tiene su punto de partida en la misma Declaración Universal de Derechos Humanos de 1948 ${ }^{37}$, cuyo preámbulo subrayaba que se consideraba «esencial que los derechos humanos sean protegidos por un régimen de derecho». La expresión régimen de Derecho, a la que se refería el preámbulo de la Declaración, debe consistir

\footnotetext{
35 MaYer-RieckH, A., op. cit., nota 12, p. 428.

${ }^{36}$ Aunque la expresión inglesa originaria sea «rule of law», los textos internacionales utilizan normalmente, en su versión en español, la expresión «Estado de Derecho» que, simplificando, podemos asimilar a otra expresión también utilizada en español en otros instrumentos internacionales, la del «imperio de la ley» o «imperio del Derecho».

37 Asamblea General de las Naciones Unidas, Resolución 217 A (III), de la Asamblea General, de 10 de diciembre de 1948.
} 
claramente en un ordenamiento jurídico interno en el que existan las garantías jurídicas y procesales necesarias y adecuadas que garanticen y permitan la efectividad de los derechos humanos proclamados en la Declaración ${ }^{38}$. Entre estas garantías jurídicas y procesales que configuran el régimen de Derecho o Estado de Derecho encuentra su lugar la independencia judicial, que evoca otro componente esencial del Estado de Derecho como es la separación de poderes ${ }^{39}$.

22. Esta incipiente conexión desde el punto de vista del Derecho internacional entre los derechos humanos, la democracia y el Estado de Derecho, como auténtica garantía de los unos y de la otra, no ha hecho más que incrementarse y eclosionar claramente a partir del fin de la guerra fría. En este sentido, en el año 2012 se celebró una Reunión de Alto Nivel de la Asamblea General precisamente sobre el Estado de Derecho, de la que emanó una Declaración sobre el Estado de Derecho en los planos nacional e internacional ${ }^{40}$. En la Declaración se reafirmaba que «los derechos humanos, el Estado de Derecho y la democracia están vinculados entre sí, se refuerzan mutuamente $\mathrm{y}$ forman parte de los valores y principios fundamentales, universales e indivisibles de las Naciones Unidas» ${ }^{41}$, constatando así una absoluta indisociabilidad entre los tres aspectos.

23. Por lo que se refiere al contenido que implica la noción de Estado de Derecho desde la perspectiva jurídica internacional debe indicarse que no existe todavía un modelo o concepto universalmente aceptado de Estado de Derecho, al igual que no lo existe de democracia y que, en todo caso, el Estado de Derecho se vincula muy directamente a diversos aspectos específicos de los derechos humanos, como la igualdad, la no discriminación, la tutela judicial o, por ejemplo, la independencia del poder judicial ${ }^{42}$. En este sentido, la independencia judicial se configura como una categoría funcional que pretende garantizar la exclusividad en el ejercicio de la actividad jurisdiccional y, por tanto, configura «la vertiente funcional de la separación de poderes y el sometimiento del operador jurídico al Derecho» ${ }^{43}$.

24. En el ámbito de la justicia transicional, el establecimiento del Estado de Derecho en situaciones de postconflicto constituye una precondición esen-

\footnotetext{
38 Véase, en este sentido, y de manera general, por ejemplo, ABELlán HonRuBiA, V., «La protección internacional de los derechos humanos: métodos internacionales y garantías internas», Pensamiento jurídico y sociedad internacional. Estudios en honor del profesor Antonio Truyol Serra, Madrid, Centro de Estudios Constitucionales, Universidad Complutense, 1986, pp. 29-58.

39 El primer Relator especial sobre el tema de la independencia de magistrados y abogados, Param Cumaraswamy, ya señaló en su Informe de 1995 que el principio de la división de poderes es «la base de los requisitos de la independencia e imparcialidad del poder judicial». Véase ONU Doc. E/ CN.4/1995/39, 6 de febrero de 1995, párr. 55.

40 Asamblea General de las Naciones Unidas, Resolución 67/1, de 24 de septiembre de 2012.

41 Ibid., párr. 6.

42 Véase CORTEN, O., «Rapport Général. L'État de droit en Droit International: quelle valeur juridique ajoutée?», L'État de droit en droit international, Colloque de Bruxelles, Société française pour le droit international, París, Ed. A. Pedone, 2009, particularmente pp. 18-24.

43 Véase, entre otros, Martínez Alarcón, M. L., La independencia judicial, Madrid, Centro de Estudios Políticos y Constitucionales, 2004, p. 67.
} 
cial para la transición del conflicto hacia una paz duradera ${ }^{44}$. El secretario general de las Naciones Unidas, en un informe de 2004, partía así de la perspectiva de que la justicia, la paz y la democracia son objetivos imperativos que se refuerzan unos a otros, de modo que es necesario fortalecer el Estado de Derecho y la justicia de transición en un contexto de postconflicto ${ }^{45}$. En este sentido, el secretario general definía el Estado de Derecho como:

«un principio de gobierno según el cual todas las personas, instituciones y entidades, públicas y privadas, incluido el propio Estado, están sometidas a unas leyes que se promulgan públicamente, se hacen cumplir por igual y se aplican con independencia, además de ser compatibles con las normas y los principios internacionales de derechos humanos. Asimismo, exige que se adopten medidas para garantizar el respeto de los principios de primacía de la ley, igualdad ante la ley, rendición de cuentas ante la ley, equidad en la aplicación de la ley, separación de poderes, participación en la adopción de decisiones, legalidad, no arbitrariedad, y transparencia procesal y legal ${ }^{46}$.

25. Se trata de una conceptualización que resulta idónea por responder a una acumulación de los componentes esenciales del Estado de Derecho. Claramente, por tanto, la noción de Estado de Derecho formulada por el secretario general se basaba en la igualdad ante la ley, la separación de poderes y la aplicación independiente de las leyes, lo que nos lleva ineludiblemente a la independencia del poder judicial como componente esencial del Estado de Derecho ${ }^{47}$. Coincidiendo con la expansión de las operaciones de paz de las Naciones Unidas, el fortalecimiento del Estado de Derecho ha ido adquiriendo un papel más relevante al considerar que promueve una paz y una seguridad sostenibles ${ }^{48}$. En otro informe de 2011, el secretario general resaltaba además la importancia de adoptar un enfoque bottom-up a la hora de promover el Estado de Derecho en contextos de justicia transicional en el que «los agentes nacionales cumplen un papel más destacado en la promoción, el diseño y la aplicación de los programas sobre el Estado de Derecho, aumentando las perspectivas para un impacto sostenible» ${ }^{49}$.

${ }^{44}$ SANnerholm, R., «Legal, judicial and administrative reforms in post-conflict societies: Beyond the rule of law template», Journal of Conflict and Security Law, vol. 12, 2007, núm. 1, pp. 65-94, esp. p. 65.

${ }^{45}$ Véase, de manera general, el completo análisis sobre esta cuestión de Villegas Delgado, C., La preeminencia del Derecho en Derecho Internacional, Aranzadi, 2013.

46 Consejo de SEguridad de las Naciones UnidAs, Informe del Secretario General, El Estado de derecho y la justicia de transición en las sociedades que sufren o han sufrido conflictos, ONU Doc. S/2004/616, de 3 de agosto de 2004, párr. 6.

47 En otro contexto internacional, el Consejo de Europa, en un informe de 2011 de la Comisión de Venecia sobre el Estado de Derecho identificó una serie de elementos necesarios de esta noción, entre los que destacan la legalidad, la seguridad jurídica, la prohibición de la arbitrariedad y el acceso a la justicia ante tribunales independientes e imparciales. Véase Report on the Rule of Law. Adopted by the Venice Commission at its 86th plenary session (Venice, 25-26 March 2011), CDL-AD (2011)003rev, Study No. 512/2009, 4 de abril de 2011, disponible en http://www.venice.coe.int/webforms/documents/? $p d f=C D L-A D(2011) 003$ rev-e.

48 Asamblea General de las Naciones Unidas, Aunar nuestras fuerzas para fortalecer el apoyo de las Naciones Unidas al Estado de Derecho o Informe del Secretario General, ONU Doc. A/61/636-S/2006/980, de 14 de diciembre de 2006, párr. 7.

49 Consejo de Seguridad de las Naciones Unidas, El Estado de derecho y la justicia de transición en las sociedades que sufren o han sufrido conflictos. Informe del Secretario General, ONU Doc. S/2011/634, de 12 de octubre de 2011, párr. 34. 
26. A estos efectos, las Naciones Unidas han elaborado asimismo un conjunto de indicadores sobre las situaciones concretas de respeto del Estado de Derecho con el fin de facilitar su implementación y su evaluación en los distintos países en conflicto o que se estabilizan tras un conflicto. Estos indicadores - hasta 135 indicadores - se centran fundamentalmente, como resulta obvio atendiendo a este enfoque postconflicto, en la perspectiva de las necesarias reformas del sector de la seguridad del Estado en cuestión y tienen tres grandes dimensiones: el sistema judicial, el sistema policial y el sistema penitenciario ${ }^{50}$. Se trata, obviamente, de tres aspectos componentes fundamentales también de la noción de Estado de Derecho, ya que la falta de seguridad y justicia configura algunos de los grandes lastres de la reconstrucción y consolidación de la paz y del desarrollo de un país que surge de un conflicto. Es por ello por lo que la reforma del poder judicial y de los organismos encargados de la seguridad constituye, en todos los casos, una absoluta prioridad. En el fondo, se trata de la cuestión fundamental del establecimiento y refuerzo de la confianza en la impartición de la justicia y en los servicios de seguridad, especialmente la policía ${ }^{51}$.

\subsection{Contenido y alcance de la independencia judicial en el Derecho internacional}

27. La idea de la independencia judicial aparece en el Derecho internacional directamente relacionada con los derechos humanos y tiene su primera enunciación en este sistema jurídico en la ya citada Declaración Universal de Derechos Humanos, cuyo art. 10 establece que: «Toda persona tiene derecho, en condiciones de plena igualdad, a ser oída públicamente y con justicia por un tribunal independiente e imparcial, para la determinación de sus derechos y obligaciones o para el examen de cualquier acusación contra ella en materia penal». Esta disposición, además de proclamar el derecho humano fundamental a la tutela judicial efectiva, también reconocido en el art. 8 de la Declaración, incorpora de manera relevante a nuestros efectos la exigencia de un tribunal independiente e imparcial para la satisfacción de este derecho humano.

28. Debe indicarse, inicialmente, que la independencia judicial implica que ni el poder judicial ni los jueces que lo integran o el juez concreto que sustancie un caso deben estar subordinados a los demás poderes públicos ${ }^{52}$,

${ }_{50}$ Véase The United Nations Rule of Law Indicators. Implementation Guide and Project Tools, United Nations 2011, disponible en http://www.un.org/en/events/peacekeepersday/2011/publications/un_rule_of_ law_indicators.pdf.

${ }_{51}$ En este sentido, nada desmoraliza más a un ciudadano o a un pueblo que está saliendo de una situación de conflicto pensar que si acude a la comisaría o al juez en busca de justicia se verá burlado y estafado si jueces y policías están al servicio, no de las víctimas, sino de los victimarios y de los criminales.

52 De lo que se trata es de que el ordenamiento jurídico, es decir, el Derecho, sea el único criterio jurídicamente relevante o "la única base de actuación del juez», a quien se confía que «decida qué norma y de qué modo debe aplicarse», sin ninguna injerencia ni subordinación. Véase REGUEJo PAGÉs, J. L., Jurisdicción e independencia judicial, Madrid, Centro de Estudios Constitucionales, 1989, p. 164. 
mientras que la imparcialidad de los jueces y tribunales — como parámetro o modelo de actitud- se refiere a la disposición de un juez o tribunal concreto con respecto a un caso y a las partes en el mismo, exigiéndoles que no tengan ideas preconcebidas sobre el caso y que no actúen de manera que se promuevan los intereses de una de las partes, es decir, ausencia de prejuicios y de parcialidad en la actividad judicial. De igual forma, el art. 14.1 del Pacto Internacional de Derechos Civiles y Políticos desarrolla este derecho humano a la tutela judicial efectiva y precisa que toda persona tiene derecho a ser oída públicamente y con las debidas garantías por un tribunal competente, independiente e imparcial, establecido por la ley. Lo que tiene una importancia esencial en la medida que, por un lado, la aplicación y garantía de los demás derechos depende en última instancia de una correcta administración de justicia; y, del otro, que la confianza pública en el sistema judicial y en la integridad del poder judicial es de vital importancia en el contexto de una sociedad democrática. Es en este sentido que puede afirmarse que sin independencia judicial no hay un juicio justo y, por tanto, no hay Estado de Derecho ${ }^{53}$.

29. Otras normas convencionales de carácter regional y declaraciones y actos jurídicos de Organizaciones internacionales regionales han recogido también el derecho a la tutela judicial efectiva, así como la exigencia de la independencia judicial ${ }^{54}$. Bajo esta perspectiva, se puede considerar también que el requisito de la independencia de los tribunales establecido convencionalmente expresa, a su vez, una costumbre internacional y un principio general de Derecho que ha acabado siendo reconocido por la comunidad internacional ${ }^{55}$. En esta misma línea deben entenderse tanto los Principios básicos relativos a la independencia de la judicatura (Principios Básicos de 1985) adoptados por el Séptimo Congreso de las Naciones Unidas sobre Prevención

53 En expresión de Lousada Arochena y Ron Latas, podría decirse que «el incumplimiento del derecho humano a la independencia judicial no solo es un incumplimiento de ese derecho, sino un incumplimiento de todo el sistema de garantía de los derechos humanos y, en general, de los derechos de todas las personas». Véase Lousada Arochena, J. F. y Ron Latas, R. P., La independencia judicial, Madrid, Dykinson, 2015, p. 58.

${ }^{54}$ Como el art. 6 del Convenio Europeo para la Protección de los Derechos Humanos y las Libertades Fundamentales; el art. 47 de la Carta de Derechos Fundamentales de la Unión Europea; los arts. 8 y 25 de la Convención Americana sobre Derechos Humanos; y el art. 26 de la Carta Africana de Derechos Humanos y de los Pueblos. Además de los textos convencionales puede indicarse, a mayor abundamiento, la Recomendación núm. R (94) 12 del Comité de Ministros del Consejo de Europa sobre la independencia, eficiencia y función de los jueces, de 13 de octubre de 1994; la Carta europea sobre el estatuto de los jueces del Consejo de Europa de 1998; los Principios y Directrices sobre el derecho a un juicio justo y a la asistencia jurídica en África, adoptados por la Comisión Africana de Derechos Humanos y de los Pueblos en 2003 o la Declaración de Beijing sobre los principios relativos a la independencia de la judicatura en la región de Asia y Pacífico (Lawasia) de 1995. Igualmente, y con el mismo tenor sobre la independencia judicial pueden citarse diversos textos adoptados por asociaciones de jueces y magistrados o en reuniones de presidentes de tribunales supremos de distintos ámbitos geográficos. Un amplio catálogo, con la reproducción de los textos legales y de los diversos estándares existentes en relación con la independencia judicial, tanto universales como regionales, puede consultarse en Principios Internacionales sobre la Independencia y Responsabilidad de Jueces, Abogados y Fiscales. Guía para profesionales núm. 1, Ginebra, Comisión Internacional de Juristas, 2007, pp. 85 y ss.

${ }_{55}$ Como subraya el Relator Especial Leandro Despouy en su Informe de 2009 sobre la independencia de los magistrados y abogados, ONU Doc. A/HRC/11/41, de 24 de marzo de 2009, párr. 14. 
del Delito y Tratamiento del Delincuente, celebrado en Milán en 1985 y confirmados por la Asamblea General de las Naciones Unidas; como los Principios de Bangalore sobre la conducta judicial de 2001 (Principios de Bangalore); como, finalmente y en particular, la Observación general núm. 32 sobre el art. 14 del Pacto adoptada por el Comité de Derechos Humanos en 2007.

30. En los Principios Básicos de 1985 se recoge expresamente en el preámbulo que la organización y administración de la justicia deben inspirarse en estos principios y que deben adoptarse medidas para hacerlos plenamente realidad ${ }^{56}$. En este sentido, la formulación de estos principios y su eje central se ciñen, precisamente, en garantizar y promover la independencia de la judicatura. Los principios se refieren a la independencia de la judicatura, la libertad de expresión y asociación de los jueces, la competencia profesional, la selección y formación de los jueces, así como a sus condiciones de servicio e inamovilidad, secreto profesional e inmunidad y medidas disciplinarias, suspensión y separación del cargo. Se desarrollan de esta forma hasta un total de 20 principios, que están presididos por el primero de ellos que establece que:

«La independencia de la judicatura será garantizada por el Estado y proclamada por la Constitución o la legislación del país. Todas las instituciones gubernamentales y de otra índole respetarán y acatarán la independencia de la judicatura».

31. El principio recoge, por tanto, el carácter primordial de la independencia de la judicatura y la obligación de todos los Estados de garantizarla y, a tal efecto, reconocerla al máximo nivel, en la misma Constitución o en la legislación interna. De manera más concreta, su proclamación en la Constitución o en la ley configura la garantía formal de la independencia judicial, mientras que su respeto y acatamiento por parte de todas las instituciones del Estado configura la garantía institucional de la misma.

32. Los Principios de Bangalore sobre la conducta judicial fueron adoptados en una reunión del año 2001 del Grupo Judicial de Reforzamiento de la Integridad Judicial en la que los presidentes de tribunales superiores de justicia reconocieron la necesidad de normas universalmente aceptables de integridad judicial. El Consejo Económico y Social consideró en el año 2006 estos Principios como complementarios a los Principios Básicos de 1985 e invitó a los Estados miembros a que los tomasen en consideración ${ }^{57}$. Destinados a garantizar y promover la independencia de la judicatura y dirigidos

\footnotetext{
56 Estos principios fueron confirmados por la Asamblea General de las Naciones Unidas en sus Resoluciones 40/32, de 19 de noviembre de 1985, y 40/146, de 13 de diciembre de 1985. Posteriormente, el Consejo Económico y Social de las Naciones Unidas adoptó la Resolución 1989/60, de 24 de mayo, sobre los «Procedimientos para la aplicación efectiva de los Principios básicos relativos a la independencia de la judicatura», que, a su vez, hizo suya la Asamblea General mediante la Resolución 44/162, de 5 de diciembre de 1989. Los Procedimientos concretan medidas específicas que deben adoptar los Estados para la implementación y realización efectiva de los Principios básicos.

57 Consejo Económico y Social, Resolución 2006/23, de 27 de julio, en cuyo anexo figuran los Principios de Bangalore.
} 
a los Estados, estos Principios pretenden establecer estándares para la conducta ética de los jueces en relación con los valores de la independencia, la imparcialidad, la integridad, la corrección, la igualdad y la competencia y diligencia; todos ellos valores fundamentales de la conducta judicial que derivan del primero de ellos, el de la independencia. A tal efecto, el primero de los Principios de Bangalore establece que:

«La independencia judicial es un requisito previo del principio de legalidad y una garantía fundamental de la existencia de un juicio justo. En consecuencia, un juez deberá defender y ejemplificar la independencia tanto en sus aspectos individuales como institucionales».

33. El núcleo central, por tanto, del principio de la independencia judicial reside en la total libertad del juez para conocer las causas sometidas a su tribunal y juzgarlas, interpretando y aplicando la ley, sin ninguna injerencia, presión, instigación, amenaza o perturbación. En todo caso, sin embargo, y a la luz de estos textos, más que considerar la independencia judicial como un privilegio o una prerrogativa del juez, se trata de entenderla como la responsabilidad impuesta a cada juez en el ejercicio de sus funciones judiciales.

34. Por su parte, en su Observación General núm. 32 sobre el art. 14 del Pacto Internacional de Derechos Civiles y Políticos el Comité de Derechos Humanos subrayó diversos aspectos relevantes en relación con la independencia de la judicatura en línea con lo establecido en los Principios Básicos de $1985^{58}$. En este sentido, el Comité apuntó que la noción de tribunal y, por extensión, de judicatura o poder judicial, «se refiere a un órgano, cualquiera que sea su denominación, creado por ley, independiente de los poderes ejecutivo y legislativo, o que goza en casos específicos de independencia judicial al decidir cuestiones jurídicas en actuaciones de carácter judicial» ${ }^{59}$. Se trata, básicamente, de dos condiciones previas imprescindibles de la independencia del poder judicial: en primer lugar, el establecimiento de los órganos judiciales mediante ley, por lo que cualquier condena o pronunciamiento por un órgano que no constituya un tribunal en este sentido resultaría incompatible con las previsiones del Pacto Internacional de Derechos Civiles y Políticos; y, en segundo lugar, que la independencia del poder judicial respecto de los otros dos poderes del Estado, el legislativo y el ejecutivo, resulta en todo caso fundamental y, en consecuencia, toda situación en la que las funciones y competencias del poder judicial y del poder ejecutivo no sean claramente distinguibles o en las que este último pueda controlar o dirigir al primero resulta incompatible con el mismo concepto de un tribunal independiente.

58 COMItÉ DE DeRechos Humanos, Observación general núm. 32, que sustituye a la Observación general núm. 13 (21. ${ }^{\circ}$ periodo de sesiones del Comité, 1984), ONU Doc. CCPR/C/GC/32, de 23 de agosto de 2007.

59 Ibid., párr. 18. El párr. 22 de la Observación general insiste en esta idea al indicar que las disposiciones del art. 14 se aplican a todos los tribunales y cortes de justicia comprendidos en su ámbito de aplicación, «sean ordinarios o especializados, civiles o militares». 
35. Además, en relación con el requisito de la independencia judicial, el Comité de Derechos Humanos consideró que este se refiere a dos aspectos: por un lado, la independencia efectiva del poder judicial respecto de la injerencia política por parte de los poderes ejecutivo y legislativo, y, por el otro, «al procedimiento y las cualificaciones para el nombramiento de los jueces, y las garantías en relación con su seguridad en el cargo hasta la edad de jubilación obligatoria o la expiración de su mandato, en los casos en que exista, las condiciones que rigen los ascensos, traslados, la suspensión y la cesión en sus funciones» ${ }^{60}$. Es decir, se trata de un enfoque que tiene una doble dimensión, institucional e individual, ya que resulta necesario garantizar la protección a los jueces en ambas dimensiones, contra los conflictos de intereses y la intimidación. En un sentido parecido, pero atendiendo a la fuente de la que pueda proceder la perturbación a la independencia judicial, podríamos referirnos, sin mayores desarrollos, a una independencia externa y a una independencia interna ${ }^{61}$.

36. La noción de independencia institucional se encuentra recogida en el Principio 1 de los Principios Básicos de 1985 relativos a la independencia de la judicatura, donde se garantiza el deber de todas las instituciones de respetar y observar dicha independencia. Lo que significa claramente tanto la independencia del poder judicial respecto de los otros poderes del Estado como la obligación de los demás poderes del Estado de respetar esta independencia y acatar y dar cumplimiento a las decisiones del poder judicial. Además de este punto de partida fundamental, puede afirmarse que el Derecho internacional, tanto por las normas internacionales sobre los derechos humanos mencionadas anteriormente como por el contenido de los Principios Básicos de 1985, los Principios de Bangalore y otros textos similares y con el mismo enfoque, contiene algunas disposiciones relacionadas con determinados aspectos esenciales de la independencia institucional del poder judicial.

37. Inicialmente, los dos aspectos más relevantes de la independencia institucional son los relacionados con la aplicación del principio de la separación de poderes, como se reconoce en la anteriormente mencionada Observación general ${ }^{62}$, y con el reconocimiento y garantía a nivel constitucional $-\mathrm{O}$ por legislación interna- de la independencia de la judicatura, de la manera que prevé el primero de los Principios Básicos de 1985. En este último sentido, incluso aunque la independencia de la judicatura estuviese consagrada en la Constitución, siguen siendo necesarias leyes nacionales en las que se observe este principio ${ }^{63}$. El resto de aspectos que configuran el contenido de la independencia institucional se refieren más bien a la organización del poder judicial, es decir, a los procedimientos de selección y nombramiento, al reconocimiento del juez natural o juez ordinario predeterminado por la ley, al

\footnotetext{
60 Comité de Derechos Humanos, Observación general núm. 32, op. cit., nota 58, párr. 19.

${ }^{61}$ Martínez Alarcón, M. L., op. cit., nota 43, pp. 123 y ss.

62 Comité de Derechos Humanos, Observación general núm. 32, op. cit., nota 58, párr. 19.

${ }^{63}$ Como subraya el Relator especial, véase ONU Doc. A/HRC/11/41, op. cit., nota 55, párr. 22.
} 
presupuesto y dotación de recursos financieros del poder judicial, a la libertad de asociación y de expresión, a los mecanismos de asignación de casos a los jueces, a la independencia en los mismos órganos de gobierno del poder judicial y al establecimiento de vías de investigación y protección en caso de denuncias por injerencias indebidas.

38. La referencia a la dimensión de la independencia individual de los jueces y magistrados que debe garantizarse por todos los Estados pretende abarcar todos aquellos elementos que afectan a la condición jurídica de los jueces tomados individualmente y que constituyen garantías en relación con su seguridad en el cargo, las condiciones de ascensos, los traslados, la suspensión y la cesación en sus funciones ${ }^{64}$. El principio más relevante y que también recogen expresamente diversos instrumentos internacionales, entre ellos los Principios Básicos de 1985, es el de la inamovilidad de los jueces hasta que cumplan la edad de jubilación forzosa o expire el periodo para el que hubieran sido nombrados o elegidos, según el caso. Esta inamovilidad constituye una los pilares fundamentales de la independencia judicial ${ }^{65}$ y solo puede ser transgredida en circunstancias excepcionales, por la aplicación de medidas disciplinarias por razones graves de mala conducta o incompetencia. Así lo recoge también la Observación general que exige, además, que se apliquen estas medidas mediante procedimientos equitativos que garanticen la objetividad y la imparcialidad y que estén establecidos en la Constitución o en la ley ${ }^{66}$.

39. Por lo que se refiere a la inmunidad, los Principios Básicos de 1985 establecen que los jueces gozarán de inmunidad personal con respecto a las acciones civiles por daños y perjuicios derivados de acciones u omisiones indebidas cometidas en el ejercicio de sus funciones judiciales, protegiendo así a los jueces de acciones judiciales injustificadas, pero asegurando, al mismo tiempo, la exigencia de responsabilidad a los jueces a fin de que no se abuse de la inmunidad. Respecto de la promoción o sistemas de ascensos de los jueces, tanto los Principios Básicos de 1985 como la Observación general reconocen que estos sistemas deben basarse en procedimientos y en criterios y factores objetivos, especialmente en la capacidad profesional, las cualificaciones, la eficiencia, la integridad y la experiencia, es decir, en méritos objetivos a valorar por órganos independientes encargados de la selección de los jueces y compuestos, a su vez, por jueces o por una mayoría de jueces. Por último, existen una serie de aspectos relacionados con las condiciones de servicio que también configuran garantías de la independencia individual: la remuneración, que debe ser adecuada y garantizada por la ley; los recursos humanos y materiales, que deben resultar adecuados y suficientes para el desempeño efectivo de las funciones judiciales; la seguridad, protegiendo a los jueces de los conflictos de intereses y la intimidación; y, finalmente, la

${ }^{64}$ Que también analiza el Relator especial en el citado Informe, ONU Doc. A/HRC/11/41, op. cit., nota 55, párrs. 52-84.

${ }^{65}$ Ibid., párr. 57.

${ }^{66}$ Comité de Derechos Humanos, Observación general núm. 32, op. cit., nota 58, párr. 20. 
formación continuada sobre la legislación nueva y vigente y sobre la jurisprudencia más reciente, que también debe ser adecuada para una función judicial eficiente e independiente y ofrecerse a los jueces a lo largo de toda su carrera judicial.

\section{LA JUSTICIA TRANSICIONAL Y EL PODER JUDICIAL}

40. Planteado el análisis de las garantías de no repetición como mecanismo de justicia transicional y abordada la independencia judicial como componente esencial del Estado de Derecho, corresponde ahora analizar, por una parte, las situaciones de complicidad del poder judicial en las graves violaciones de los derechos humanos en el pasado (4.1); y, de otra, las necesarias reformas del poder judicial, precisamente, como garantía de no repetición (4.2).

\subsection{La complicidad del poder judicial en las graves violaciones de los derechos humanos}

41. La complicidad del sistema judicial ante las graves violaciones de los derechos humanos se ha dado tanto en contexto de regímenes autoritarios como en situaciones de conflicto armado. A este respecto, varias comisiones de la verdad han revelado el papel del poder judicial en estas situaciones en las que a menudo, como ya hemos indicado, miró para otro lado, no tramitó los recursos de habeas corpus interpuestos por las víctimas o no practicó las investigaciones en tiempo y forma que implicaban a las fuerzas armadas o al poder ejecutivo, bien por su afinidad al poder o bajo amenaza de represalias. Aun así, la doctrina prácticamente no ha analizado la relación entre la complicidad del sistema judicial en las atrocidades del pasado y la necesidad de reformar el sistema como mecanismo de prevención y garantía de no repetición de violaciones de derechos humanos en el futuro y se ha centrado más en la celebración de juicios a las personas responsables de estos crímenes.

42. En este sentido, distintos factores pueden poner en entredicho la independencia judicial en contextos de justicia transicional como, por ejemplo, la continuidad de jueces que operaron con el régimen anterior que, junto con los nuevos jueces, deberán tener un compromiso con el nuevo régimen. En concreto puede ocurrir que los jueces tengan que decidir sobre cuestiones con repercusiones políticas importantes, como puede ser el hecho de determinar la legalidad de las nuevas leyes adoptadas por el Estado en transición para afrontar los delitos del pasado que, de alguna forma, eran legales con el régimen jurídico anterior ${ }^{67}$. Así, la complicidad del poder judicial con las

67 Dyzenhaus, D., «Judidical Independence, Transitional Justice and the Rule of Law», Otago Law Review, vol. 10, 2003, pp. 345-369, esp. p. 347. Véanse, por ejemplo, los argumentos del Tribunal Supremo español para no invalidar la ley de amnistía de 1977 que impide la investigación de los crímenes del franquismo: «Los jueces, sujetos al principio de legalidad no pueden, en ningún caso, derogar leyes 
atrocidades del pasado podría explicar la reticencia de los tribunales españoles a declarar nulos los consejos de guerra que se llevaron a cabo sin ningún tipo de garantías judiciales durante el franquismo por considerar que «la legislación que se aplicó en el momento de dictarse la sentencia cuya revisión se pretende era [...] la vigente en el momento de su aplicación, sin que pueda alegarse error iuris en este recurso» ${ }^{68}$. Esto también explicaría cómo, frecuentemente, los regímenes autoritarios recurren al discurso del Estado de Derecho para legitimar su narrativa y puede ocurrir que, en estos contextos, el sistema judicial tenga una independencia formal en relación con los nombramientos, y promociones de los jueces y, sin embargo, se enfrente a una forma corporativista de control político que puede ser igual de opresiva cuando se practica dentro del poder judicial ${ }^{69}$.

43. En Argentina, durante la dictadura (1976-1983) los jueces y fiscales rechazaban de forma sistemática el recurso habeas corpus interpuesto por casos de desapariciones forzadas y además imponían las costas a las familias que denunciaban tales hechos como forma de intimidación y para desalentar la presentación de recursos ante los tribunales ${ }^{70}$. De modo que los jueces y fiscales en Argentina solamente instruían expedientes en los que el procedimiento penal estaba destinado a condenar a los subversivos sin las debidas garantías judiciales, garantizando así la impunidad total de los agentes del Estado. En consecuencia, los jueces y fiscales aplicaron las leyes "sin preguntarse si eran constitucionales o si violaban principios fundamentales del Derecho internacional de los derechos humanos». Pero, sin duda, se trataba de «Leyes dictadas por un poder de facto, que permitían instruir expedientes mediante los cuales se daba una apariencia de legalidad a los actos de terrorismo de Estado» ${ }^{71}$.

44. En el Perú, la Comisión de la Verdad y Reconciliación afirmó que el sistema judicial «no cumplió con su misión adecuadamente [...] para poner coto a la impunidad en que actuaban los agentes del Estado que cometían graves violaciones de los derechos humanos ${ }^{72}$. Asimismo, en El Salvador, la Comisión de la Verdad constató que el sistema judicial fue debilitado, sobre todo a partir de las amenazas recibidas y la corrupción. Además, el poder judicial «nunca había gozado de una verdadera independencia institucional

cuya abrogación es exclusiva competencia del poder legislativo [...] ha de recordarse que la ley de amnistía fue promulgada con el consenso total de las fuerzas políticas en un periodo constituyente surgido de las elecciones democráticas de 1977», STS 101/2012, de 27 de febrero, FJ 3.

68 Véase, entre otros, el caso de José Pellicer, ATS 10099/2006 (Sala 5. a , de lo Militar) de 20 de junio de 2006, FJ 2, por el que se rechaza la solicitud de revisión del proceso.

69 Moustafa, T., "Law and Courts in Authoritarian Regimes», Annual Review of Law and Social Science, vol. 10, 2014, núm. 1, pp. 281-299, esp. p. 290.

70 Cámara Federal de Apelaciones de Mendoza, «Compulsa de As.636-F (F. c/ Guzzo, Miret, Petra, Romano, Carrizo)», de 18 de mayo de 2011.

71 Salinas, P. G., «Juicio a los jueces y fiscales de Mendoza», en BohosLavsky, J. P., ¿Usted también, doctor? Complicidad de jueces, fiscales y abogados durante la dictadura, Buenos Aires, Siglo Veintiuno Editores, 2015, pp. 197-213, esp. p. 203.

72 COMisión de la Verdad y Reconciliación, Informe final: recomendaciones, de 28 de agosto de 2003. 
de las ramas legislativa y ejecutiva, su ineficacia no hizo sino incrementarse hasta convertirse, por su inacción o actitud de lamentable supeditación, en factor coadyuvante de la tragedia que ha sufrido este país ${ }^{73}$.

45. Por otra parte, la Comisión para el Esclarecimiento Histórico llegó a la conclusión en su informe final de que, en Guatemala, entre 1966 y 1982, el poder judicial «denegó sistemáticamente el recurso de habeas corpus y la protección judicial efectiva de las personas ilegalmente detenidas por las fuerzas de seguridad» ${ }^{74}$. En general, los tribunales de justicia actuaron claramente subordinados al poder ejecutivo, aplicando normas o disposiciones legales contrarias al debido proceso u omitiendo aplicar las que correspondían ${ }^{75}$.

46. En España, si bien la justicia ordinaria sí se podía considerar independiente durante la dictadura, en verdad carecía de relevancia puesto que eran las jurisdicciones especiales, como la militar y el Tribunal de Orden Público, las que verdaderamente se encargaban de los delitos políticos y cuyos jueces eran nombrados y removidos directamente por el poder ejecutivo ${ }^{76}$. Como explica Paloma Aguilar, durante la dictadura franquista, el sistema judicial:

«no se limitó a mantener un silencio cómplice ante las violaciones de derechos, sino que fue una pieza fundamental de la maquinaria represiva, sobre todo a través de su participación directa en los consejos de guerra y en las jurisdicciones especiales que se crearon a propósito" ${ }^{77}$.

47. Otro importante precedente es el juicio a jueces celebrado tras la Segunda Guerra Mundial por los tribunales militares estadounidenses en Núremberg, en el que se condenó a dos jueces por haber participado y contribuido en la comisión de crímenes de guerra y de lesa humanidad. Durante el proceso judicial se constató que el sistema nazi obligó a los jueces a situarse en una de las dos categorías siguientes. En la primera, había jueces que aún conservaron ideales de la independencia judicial y que administraron justicia con imparcialidad y moderación. Sin embargo, las sentencias que dictaron fueron dejadas de lado a través de declaraciones de nulidad y la objeción extraordinaria, de modo que las personas condenadas fueron frecuentemente transferidas a la Gestapo al completar la pena de prisión y luego fusiladas o

73 COMIsión de la Verdad, De la locura a la esperanza. La guerra de 12 años en el Salvador, Informe final, S/25500, Anexo, 1 de abril de 1993.

74 COMISIÓN PARA El Esclarecimiento Histórico, Guatemala memoria de silencio, junio de 1999, párr. 2701.

75 Ibid., párr. 2634.

76 Toharia, J. J., «Judicial Independence in an Authoritarian Regime: The Case of Contemporary Spain», Law and Society Review, vol. 9, 1975, pp. 475-496, esp. p. 487.

77 Aguilar, P., «Jueces, represión y justicia transicional en España, Chile y Argentina», Revista Internacional de Sociología, vol. 71, mayo-agosto de 2012, núm. 2, pp. 281-308, esp. p. 284. Cabe destacar la Ley 11/2017, de reparación jurídica de víctimas del franquismo, adoptada por el parlamento catalán por unanimidad el 4 de julio de 2017, que declara nulas de pleno Derecho todas las sentencias y resoluciones de las causas instruidas y de los consejos de guerra dictadas por causas políticas en Cataluña por el régimen franquista entre 1938 y 1978, cuyo número asciende a 65.590, lo cual refleja el alcance de la complicidad del poder judicial durante el franquismo. 
enviadas a campos de concentración. Asimismo, los propios jueces fueron amenazados y criticados e incluso removidos. En la otra categoría estaban los jueces que con celo fanático hicieron cumplir la voluntad del Partido Nazi con tal severidad que no experimentaron dificultades y poca interferencia de los oficiales del partido. Para el Tribunal Militar de Núremberg, los Jueces Rothaug y Oeschey pertenecían a esta segunda categoría ${ }^{78}$.

48. Vista la complicidad del poder judicial ante las graves violaciones de los derechos humanos ocurridas tanto en contexto armado como de regímenes dictatoriales, Hakeem Olayinka Yusuf considera que es fundamental rendir cuentas sobre el sistema judicial ya que, lejos de comprometer su independencia, esta rendición de cuentas la refuerza. Para el autor, el escrutinio del papel del poder judicial en el pasado tiene un doble objetivo: por una parte, permite tener un registro del rol que tuvo el sistema judicial en el pasado como institución y, por otra, el hecho de conocer la implicación del poder judicial puede facilitar la transformación de la institución en el periodo de transición para que no vuelvan a ocurrir los mismos hechos, constituyendo así una garantía de no repetición. De modo que la asunción de responsabilidad del poder judicial por crímenes del pasado puede considerarse que contribuye directamente a fortalecer, y no a debilitar, su independencia judicial ${ }^{79}$.

49. No debieron pensar así los jueces sudafricanos, puesto que ningún juez compareció ante la Comisión de la Verdad y Reconciliación de Sudáfrica en la audiencia legal. Si bien algunos de ellos presentaron sus alegaciones por escrito ${ }^{80}$, muchos otros no comparecieron porque consideraron que una investigación oficial podría comprometer su independencia y romper la frágil relación colegial que había entre los jueces del antiguo régimen que mantenían sus puestos y los nuevos jueces ${ }^{81}$. No obstante, Hakeem Olayinka Yusuf incluso va más allá y afirma que no abordar la responsabilidad del sistema judicial por su papel durante el periodo autoritario o de conflicto armado pone en peligro la transformación del Estado ${ }^{82}$. Considera, en este sentido, que cuanto mayor es la implicación del sistema judicial en las atrocidades del pasado, más resistencia ofrecerá a las iniciativas de justicia transicional de esclarecimiento de la verdad o de revisión judicial del pasado, porque la reputación y profesionalidad del sistema judicial podría resultar perjudicada ${ }^{83}$.

${ }^{78}$ The Justice Case (Military Tribunal III, case 3, The United States of America against Josef Altstoetter, Wilhelm von Am Bcmon, Paul Barnickel, Hermann Cuhorst, Karl Engert, Guenther Joel, Herbert Klemm, Ernst Lautz, Wolfgang Mettgenberg, Guenther Nebelung, Rudolf Oeschey, Hans Petersen, Oswald Rothaug, Curt Rothenberger, Franz Schlegelberger, and Carl Wastphal), en IMT, Trials of War Criminals before the Nurenberg Military Tribunals under Control Council Law N. ${ }^{\circ} 10$, vol. III, Washington, U.S. Government Printing Office, 1951, p. 1025.

79 Yusuf, H. O., Transitional Justice, Judicial Accountability and the Rule of Law, Routledge, 2013, pp. 26-27.

${ }^{80}$ Véase Truth and Reconciliation Commission of South Africa Report, vol. 4, cap. 4, sobre «Institutional hearing: The Legal Community», 1998, p. 93.

81 Dyzenhaus, D., op. cit., nota 67, p. 349.

82 Yusuf, H. O., op. cit., nota 79, p. 183.

83 Aguilar, P., op. cit., nota 77, p. 284. 


\subsection{Las reformas del poder judicial como garantía de no repetición}

50. En situaciones de postconflicto debe tenerse en cuenta, inicialmente, que las reformas institucionales requieren varias generaciones y son a largo plazo, mientras que en los Estados en transición se priorizan a menudo las cuestiones de seguridad y estabilidad por encima de las reformas institucionales, dejando estas para más adelante. En la medida en que la justicia transicional promueve el Estado de Derecho en las nuevas democracias o en situaciones de postconflicto, la reforma del poder judicial para que recupere su legitimidad, su independencia e imparcialidad, así como su credibilidad pública, resulta indispensable ${ }^{84}$. La independencia judicial se configura, así, como un elemento esencial de la democracia y el Estado de Derecho y cobra mayor significado en países que han sufrido un pasado violento o autoritario, donde históricamente el poder judicial ha estado sometido al poder político o militar. En este sentido, el Estado de Derecho puede que no sea la primera víctima en tiempo de conflicto armado, pero a menudo es el más difícil de restablecer ${ }^{85}$. Podemos entender, así, que, en general, la democracia y la independencia judicial tienden a asociarse, al considerarse que la primera es una condición previa, aunque no suficiente, para la segunda ${ }^{86}$, pese a que hay algunos autores que cuestionan que la independencia judicial sea un prerequisito indispensable para el Estado de Derecho en la construcción de nuevas democracias ${ }^{87}$. En definitiva, no hay duda de que la reconstrucción más difícil en situaciones de transición y postconflicto es la inmaterial, es decir, la de restaurar la confianza de las personas en la sociedad y en el conjunto de las instituciones del Estado ${ }^{88}$.

51. En general, las reformas institucionales son cuestiones de por sí complicadas y más aún en un contexto de justicia transicional en el que la judicatura ha sido cómplice de las violaciones de los derechos humanos del pasado. Por otra parte, el fracaso en un área del Estado de Derecho puede tener un impacto negativo en otras áreas en las que se había avanzado ${ }^{89}$. De modo que de nada sirve reforzar la eficacia del poder judicial si la policía no

\footnotetext{
${ }^{84}$ Comisión de Derechos Humanos, Informe del Relator Especial sobre la independencia de los magistrados y abogados, Leandro Despouy, ONU Doc. E/CN.4/2005/60, de 20 de enero de 2005, párr. 44.

${ }^{85}$ LoRenz, F. M., "Civil-Military Cooperation in Restoring the Rule of Law: Case Studies from Mogadishu to Motrovica», en Bassiouni, M. Ch. (ed.), Post-conflict Justice, NY, Transnational Publishers Inc., Ardsley, 2002, pp. 829-849, esp. p. 829.

${ }_{86}$ TOHARIA, J. J., op. cit., nota 76, p. 475.

87 FinN, J. E., «The Rule of Law and Judicial Independence in Newly Democratic Regimes», Good Society Journal, vol. 13, 2004, núm. 3, pp. 12-16; HelmKe, G. y Rosenbluth, F., «Regimes and the Rule of Law: Judicial Independence in Comparative Perspective», Annual Review of Political Science, vol. 12, 2009, núm. 1, pp. 345-366, esp. p. 361.

88 Farrall, J., «Impossible expectations? The UN Security Council's Promotion of the Rule of Law after Conflict», en Bowden, B., Charlesworth, H. y Farrall, J. (eds.), The Role of International Law in rebuilding Societies after Conflict, Cambridge, Cambridge University Press, 2009, pp. 138 y 155.

89 International Council on Human Rights Policy, Negotiating Justice? Human Rights and Peace Agreements, Ginebra, ICHRP, 2006, p. 104.
} 
tiene la capacidad de investigar y no hay prisiones seguras ${ }^{90} \mathrm{o}$, a la inversa, tener una policía que detiene a los criminales conforme a la legislación y nueva Constitución si el sistema judicial está colapsado y no tiene la capacidad para procesar con las debidas garantías a los criminales ${ }^{91}$. Sin embargo, Elin Skaar considera que las reformas constitucionales han contribuido a que los jueces sean más proclives a juzgar a los militares responsables de graves violaciones de los derechos humanos al ser más independientes del poder ejecutivo (dimensión institucional) así como menos dependientes dentro de la jerarquía del sistema judicial (dimensión individual) ${ }^{92}$.

52. El desafío en estos contextos es, precisamente, construir un sistema judicial fuerte e independiente, que no permita la injerencia del poder político ni de las élites de poder ${ }^{93}$. Sin embargo, las reformas institucionales del poder judicial conllevan, en cierta medida, la creencia excesiva de la inclinación de los jueces hacia el cambio y la asunción de que los profesionales del Derecho pueden actuar como transformadores sociales ${ }^{94}$. Por otra parte, si bien en general se consigue una independencia formal del poder judicial a través de la adopción o reforma de la Constitución y las leyes internas, esto no se traduce necesariamente en una independencia real o de facto del sistema judicial.

53. En este sentido, si bien hay que atender al caso particular y a los recursos disponibles, las diferentes medidas para fortalecer el poder judicial deben tener tres objetivos fundamentales: sacar del sistema judicial a los jueces y auxiliares de justicia identificados con el régimen anterior; proteger a los jueces de posibles arbitrariedades o medidas de remoción indiscriminadas; y, garantizar que los jueces formen un cuerpo homogéneo, de probada integridad y de conducta notoriamente irreprochable ${ }^{95}$. Es por este motivo que la justicia transicional debe promover la sanción y remoción de los jueces que participaron en los crímenes del pasado, para prevenir que estas mismas personas sean las que juzguen a los criminales

90 Esta era la situación de Guatemala después del conflicto armado en la que la policía no tenía los medios para investigar los delitos y no había ninguna prisión segura y los presos podían entrar y salir de ella a su antojo. De modo que las reformas del poder judicial tenían que ir acompañadas necesariamente de una nueva policía y el establecimiento de prisiones seguras. Véase, entre otros, WOLA, $L a$ CICIG: un instrumento innovador contra redes criminales y para el fortalecimiento del Estado de derecho, Informe 3/2015, Washington D. C., marzo de 2015.

91 Este fue el caso de Haití, Ruanda, Kosovo y Timor Oriental, en el que se pudo crear una nueva policía, pero el sistema judicial aún era muy precario, de modo que la policía empezó a arrestar a criminales que empezaron a acumularse en las prisiones y que finalmente tuvieron que ser puestos en libertad porque la justicia no tenía la capacidad para juzgarlos. Véase INTERNATIONAL CoUnCIL ON HUMAN Rights Policy, op. cit., nota 89, p. 104.

${ }_{92}$ SKAAR, E., op. cit., nota 3, p. 16. El estudio se basa solamente en países de Latinoamérica.

93 ImpUnITY WATch, Estrategias de incidencia ciudadana para monitorear procesos de elección de magistrados, 2015.

${ }_{94}$ SANNERHOLM, R., Rule of Law after war and crisis: ideologies, norms and methods, Intersentia, 2012, p. 159. El autor utiliza la expresión «legal professionals [...] as social engineers».

95 Comisión de Derechos Humanos, Informe del Relato Especial sobre la independencia de los magistrados y abogados, Leandro Despouy, ONU Doc. E/CN.4/2006/52, de 23 de enero de 2006, párr. 50. 
y participen en los programas de reparación destinados a las víctimas y sus familiares ${ }^{96}$.

54. En efecto, en contextos de justicia transicional se manifiesta claramente el problema de las situaciones en donde se mantiene la existencia de amplios sectores del poder judicial que han estado implicados, directa o indirectamente, en el proceso político anterior - $-\mathrm{y}$ en violaciones de los derechos humanos - y cuya continuidad en el ejercicio de las funciones judiciales erosionaría gravemente la credibilidad y la confianza en la articulación institucional del poder judicial en una sociedad que aspira a ser democrática. A este respecto y con esta misma perspectiva - la de procurar que las instituciones públicas se organicen de tal manera que se asegure el respeto por el Estado de Derecho y la protección de los derechos humanos-, debe indicarse que el Principio 36 del Conjunto de Principios contra la Impunidad prevé con respecto al poder judicial, que «los Estados deben emprender todas las medidas necesarias para asegurar el funcionamiento independiente, imparcial y eficaz de los tribunales de conformidad con las normas internacionales relativas a las garantías procesales debidas».

55. Estos aspectos fueron ampliamente analizados en el Informe de 2009 del Relator especial sobre la independencia de los magistrados y abogados sobre la base de los instrumentos internacionales existentes, de las opiniones de los órganos de los tratados sobre derechos humanos y de la misma práctica internacional ${ }^{97}$. En todo caso, pueden destacarse algunos aspectos: pese a la diversidad de procedimientos de selección existentes en los diferentes Estados, para fomentar la confianza en el sistema judicial deberían utilizarse sistemas de selección objetivos, justos e independientes, evitando interferencias externas de carácter político o de otra índole; además, todos los Estados deberían proporcionar recursos económicos suficientes para que la judicatura pudiese desempeñar debidamente sus funciones y sería preferible que la administración de los fondos se encomendase directamente al poder judicial o a un órgano independiente encargado de la judicatura; finalmente, resulta pertinente subrayar que debería protegerse también la independencia de los jueces, no tan solo de las injerencias externas sino también de las injerencias internas, estableciéndose mecanismos de elección de las jerarquías judiciales internas y procedimientos preestablecidos de asignación de casos a los jueces.

56. En el contexto de la justicia transicional, en relación con el problema de los jueces y magistrados involucrados en el proceso anterior, el mismo Principio 36 establece que los funcionarios públicos y los empleados que sean «personalmente responsables de violaciones graves de los derechos humanos, en particular los que pertenezcan a los sectores militar, de seguridad,

96 Almovist, J., "Complicidad judicial como cuestión de derecho internacional», en BoHosLAVSKY, J. P., ¿Usted también, doctor? Complicidad de jueces, fiscales y abogados durante la dictadura, Buenos Aires, Siglo Veintiuno Editores, 2015, pp. 291-301, esp. p. 301.

97 Véase ONU Doc. A/HRC/11/41, op. cit., nota 55, párrs. 17-51. 
policial, de inteligencia y judicial, no deben continuar al servicio de las instituciones del Estado» ${ }^{98}$.

57. Esta posibilidad de destitución, que constituye claramente una restricción al principio de la inamovilidad de los jueces, está también limitada o restringida en los mismos Principios. Así, en el Principio 30 se reconoce que la inamovilidad es una garantía fundamental de la independencia de los jueces que «deberá respetarse en el caso de los magistrados que hayan sido nombrados de conformidad con los requisitos de un Estado de Derecho", pero no en relación con los otros, que podrán ser destituidos en virtud de la ley y en aplicación del principio del paralelismo de las formas. En todo caso, esta destitución deberá realizarse ofreciendo a la persona afectada la oportunidad de impugnar la destitución y siguiendo procedimientos que atiendan, asimismo, a los criterios de independencia e imparcialidad con miras a pedir su reincorporación ${ }^{99}$. Se trata, en definitiva, de impedir abusos y ajustes de cuentas, aunque solo sea —más allá de las situaciones individuales- para evitar que se reproduzca la situación anterior y para conseguir que la justicia mejore en autoridad y credibilidad ${ }^{100}$. A este respecto, el Principio 36 señala asimismo que, en cualquier caso, la destitución de estas personas «se realizará de acuerdo con los requisitos del debido proceso y el principio de no discriminación».

58. En relación con esta misma compleja situación, el Relator especial sobre la independencia de magistrados y abogados se inclinaba en su Informe de 2006 por la fórmula de la revisión prefiriéndola a la reasignación de los jueces ${ }^{101}$. La reasignación supone la destitución en bloque del personal afectado y la obligación de volver a competir por el puesto, mientras que la revisión implica un análisis individualizado de cada caso y la garantía de que puedan sustanciarse por órganos judiciales superiores los recursos de apelación que, en su caso, se interpongan. Fórmulas individualizadas que pueden suponer diversas medidas disciplinarias, incluso la remoción, pero que, como indicaba el Relator especial, han de resultar respetuosas con los Principios Básicos de 1985 relativos a la independencia de la judicatura ${ }^{102}$. En este sentido, estos Principios resultan plenamente coherentes con el Conjunto de los Principios contra la Impunidad.

98 La cursiva es nuestra.

99 Véase Conjunto de principios actualizado..., op. cit., nota 1, Principio 30.

100 Comisión de Derechos Humanos, ONU Doc. E/CN.4/2005/60, op. cit., nota 84, párr. 45.

101 Comisión de Derechos Humanos, ONU Doc. E/CN.4/2006/52, op. cit., nota 95, párr. 54.

102 Los Principios básicos establecen la obligación general de los Estados de respetar la independencia judicial en todo caso y, particularmente, el Principio 20 dispone que «las decisiones que se adopten en los procedimientos disciplinarios, de suspensión o de separación del cargo, estarán sujetas a una revisión independiente». 


\section{CONSIDERACIONES FINALES}

59. A título de consideraciones finales debe subrayarse, en primer lugar, la absoluta necesidad de que los Estados en transición adopten garantías de no repetición para prevenir que vuelvan a ocurrir las graves violaciones de los derechos humanos del pasado. En este sentido, en el ámbito de la justicia transicional, las garantías de no repetición pueden considerarse una forma de reparación en un sentido amplio o como una medida separada, pero, en todo caso, se caracterizan por ser medidas que miran hacia el futuro, de carácter preventivo y que tiene por objeto evitar la repetición de las violaciones de derechos humanos ocurridas en el pasado. Dentro de las diferentes garantías de no repetición, el Derecho internacional incluye como elemento esencial el fortalecimiento de la independencia del poder judicial. Sin embargo, a menudo, los jueces han sido cómplices de las graves violaciones durante el conflicto armado o régimen autoritario, de modo que en los procesos de justicia transicional las diferentes reformas del poder judicial deberían cumplir una triple finalidad: sacar del sistema judicial a los operadores de justicia identificados con el régimen anterior; proteger a los jueces de posibles arbitrariedades o medidas indiscriminadas; $y$, finalmente, garantizar que los jueces formen un cuerpo homogéneo, de probada integridad y conducta impecable.

60. En segundo lugar, debe indicarse también que los textos internacionales en materia de derechos humanos han situado en el plano internacional el derecho humano a la tutela judicial efectiva y, en este contexto, han situado también el derecho humano a la independencia judicial, sin el cual, ni aquel ni los otros derechos humanos pueden ser realmente efectivos. Si el Estado de Derecho constituye la garantía de los derechos humanos y de la democracia, la independencia judicial conforma el núcleo esencial de las garantías jurídicas y judiciales de los unos y de la otra. En efecto, como hemos señalado en este estudio, la aplicación y garantía de los derechos humanos depende en última instancia de una correcta administración de justicia. En este marco, la independencia judicial pretende garantizar la separación de poderes y la exclusividad en el ejercicio de la actividad jurisdiccional por parte de los jueces, es decir, su sometimiento exclusivo a la ley en la función judicial de conocer y dictar sentencia en un determinado asunto, protegidos de cualquier injerencia o intromisión. En última instancia, por tanto, reforzar la independencia del poder judicial contribuye al establecimiento del Estado de Derecho y al respeto de los derechos humanos. De ahí la necesidad de garantizar tanto la dimensión institucional como la dimensión individual de la independencia judicial.

61. En tercer lugar, debe ponerse de manifiesto que la independencia judicial se configura como un elemento fundamental para generar credibilidad y confianza por parte de la ciudadanía en la administración de justicia y en los mecanismos del Estado de Derecho. Si esta confianza es en todo caso necesaria en sociedades democráticas, se revela más necesaria si cabe en situa- 
ciones de transición hacia la democracia o la paz después de conflictos. Estas situaciones requieren una nueva institucionalidad democrática y un Estado de Derecho que ha de desarrollarse de manera estable y sostenida, con el apoyo y la confianza de la ciudadanía y, por tanto, entre otros aspectos, ha de tener como uno de sus componentes esenciales la independencia judicial. Finalmente, en estos contextos de situaciones de transición sucede a menudo que la inamovilidad de los jueces, que constituye una de las garantías fundamentales de la independencia judicial, tiene que ceder — con todas las garantías jurídicas- precisamente en interés de la buena imagen y de la integridad de la justicia y para evitar que jueces vinculados al proceso anterior puedan seguir ejerciendo funciones judiciales.

\section{RESUMEN}

\section{EL FORTALECIMIENTO DE LA INDEPENDENCIA JUDICIAL EN LOS PROCESOS DE JUSTICIA TRANSICIONAL COMO GARANTÍA DE NO REPETICIÓN}

Las garantías de no repetición comprenden todas las medidas que debe adoptar un Estado en transición para prevenir que se repitan las graves violaciones de derechos humanos ocurridas en el pasado. El objeto de este estudio es analizar, desde la perspectiva del Derecho internacional, en qué medida las reformas institucionales encaminadas a fortalecer la independencia judicial en procesos de justicia transicional constituyen garantías de no repetición. En este sentido, el Derecho internacional ofrece un conjunto de normas y principios para garantizar la independencia judicial, tanto en su dimensión institucional como individual. Por otra parte, el poder judicial a menudo ha sido cómplice de las violaciones de derechos humanos cometidas en el pasado, de modo que las diferentes medidas durante la transición deberían cumplir una triple finalidad: sacar del sistema judicial a los operadores de justicia identificados con el régimen anterior, proteger a los jueces de posibles arbitrariedades o medidas indiscriminadas y, garantizar que los jueces formen un cuerpo homogéneo, de probada integridad y conducta impecable. En última instancia, el fortalecimiento de la independencia judicial no solo contribuye a prevenir futuras violaciones de derechos humanos, sino que también aumenta la confianza de la ciudadanía en las instituciones y refuerza el Estado de Derecho.

Palabras clave: justicia transicional, garantías de no repetición, reformas institucionales, independencia judicial, Estado de Derecho.

\section{ABSTRACT \\ STRENGTHENING JUDICIAL INDEPENDENCE IN TRANSITIONAL JUSTICE AS A GUARANTEE OF NON-REPETITION}

The guarantees of non-repetition include all the measures that a State in transition must adopt to prevent the recurrence of serious violations of human rights that occurred in the past. The purpose of this study is to analyze, from an International Law perspective, to what extent institutional reforms aimed at strengthening judicial independence in transitional justice constitute guarantees of non-repetition. In this sense, International Law offers a set of rules and principles to guarantee judicial independence, both in its institutional and individual dimensions. On the other hand, the judiciary has often been accomplice in human rights violations committed in the past, therefore, transitional justice 
measures should serve a threefold purpose: removing justice operators from the judicial system identified with the previous regime, protect judges from possible arbitrariness or indiscriminate measures and, finally, ensure that judges form a homogeneous body, with proven integrity and impeccable conduct. Eventually, strengthening judicial independence in transitional justice not only contributes to prevent future human rights violations, but also increases citizens' trust in institutions and promotes the rule of law.

Keywords: transitional justice, guarantees of non-repetition, institutional reforms, judicial independence, rule of law. 